\section{Germany cuts funds for joint work with eastern Europe}

[MUNICH] Germany's main research grantgiving body, the Deutsche Forschungsgemeinschaft (DFG), has decided to cut by a third its financial support for joint research projects between scientists from Germany and from central and eastern Europe.

The DFG's annual budget of more than DM1 billion (US $\$ 581$ million) comes from Germany's federal government. Although it is due to increase by 5 per cent over the next four years, the DM5-million now allocated to building scientific links with scientists from Russia and 20 other east and central European countries has been reduced by more than one third, to DM3.3 million.

The cuts take effect immediately. Cooperation with Russia will in particular suffer a significant setback, as the DFG had planned around 220 joint research projects with the Russian Foundation for Basic Research and the Russian Academy of Sciences this year, including bilateral scientific symposia.

"The cuts hit us at a time when our cooperation activities are becoming increasingly effective, as the criterion of scientific excellence has recently been taking precedence over political considerations in Russia," says Doris Schenk, the DFG official responsible for scientific collaboration with central and eastern Europe and the former Soviet Union.

Some Russian research institutes have become accessible to Western scientists only in the past four years. Before that, the toplevel Russian researchers who worked in them - mostly theoretical physicists, mathematicians and chemists - were neither allowed to travel nor to publish their results.

"In many cases, we did not even know the names of these scientists," says Schenk. With DFG support they have been able to attend meetings and conferences in Germany to meet Western colleagues, often for the first time, and to become familiar with international scientific procedures.

But this process of rapprochement could now begin to decline. Germany's research minister, Jürgen Rüttgers, has announced a further cut in funds for the programme over the next three years. Schenk says: "This is a short-sighted policy since international collaborations with what used to be difficult partners need long-term continuity."

DFG officials are confident that they will be able to find money from within this year's budget to meet the contractual commitments for collaborative efforts to which they have already argeed. But they emphasize that this can only be done on a temporary basis by diverting the money from other activities, and that it does not represent a long-term solution.

\title{
Japan calls in outside help to reform nuclear efforts
}

[TOKYO] Japan's beleaguered Science and Technology Agency (STA) is planning to call in foreign management consultants to carry out a complete review of the management of the Power Reactor and Nuclear Fuel Corporation (PNC). This unprecedented move follows a series of accidents at the corporation's nuclear facilities.

STA is under pressure to make radical changes at PNC, a semi-public organization under its jurisdiction with responsibility for a much of Japan's nuclear power research programme. PNC has been plagued with problems, leading to calls for it to be disbanded (see Nature 386, 746; 1997).

The STA is considering various foreign consultancy companies, including Arthur Andersen, one of the world's largest management consultants. According to STA officials, Japanese consultants are too "cosy" with the establishment to provide the independence needed of a third-party review.

The decision to review PNC's performance follows disclosures that PNC officials falsified reports about an explosion at a facility used for bitumenization of low-level radioactive waste at a nuclear fuel recycling plant in Tokai, northeast of Tokyo. The explosion exposed 37 PNC workers to low doses of radiation (see Nature 386, 209; 1997).

A preliminary report on the incident released by STA last week says the fire in drums used for storing nuclear waste was probably caused by a reaction between sodi- um nitrate and sodium phosphate (in radioactive waste fluid) and asphalt used to solidify the nuclear waste. PNC had changed the procedure a few days before the accident, reducing the amount of asphalt used. According to Kaname Ikeda, director-general of STA's nuclear safety bureau, this may have led to "the troubles" that caused the fire.

The report states that a failure to extinguish the fire properly probably caused the explosion ten hours later. Ikeda says that there is a "defect in the management" which prevented the dissemination of knowledge and past experience to staff.

STA acknowledges for the first time in the report its own responsibility for the accident in not providing sufficient guidance to PNC. The agency has filed a criminal complaint against the organization and against PNC officials who tried to cover up false claims that the fire was immediately extinguished.

The consultants will be asked to focus on crisis management and notification systems in their review. Many analysts argue that Japan lacks sufficient expertise in crisis management. This was highlighted by the government's slow reaction to the Kobe earthquake in 1995, and the more recent disorganized response to an oil spill from a Russian tanker off the coast of Shimane Prefecture.

The consultants' report will be submitted to the recently formed PNC reform committee, headed by Horiyuki Yoshikawa, former president of Tokyo University. RichardNathan

\section{Synchrotron to move to science institute?}

[TOKYO] The reorganization of Japan's Power Reactor and Nuclear Fuel Corporation (PNC) is likely to have farreaching implications for other research organizations for which the Science and Technology Agency (STA) is responsible.

Serious consideration is being given to transferring some of PNC's responsibilities to the Japan Atomic Energy Research Institute (JAERI).

This might have a knockon effect on the Institute of Physical and Chemical Research (RIKEN), which jointly runs SPring-8, the largest synchrotron in the world, with JAERI. In one scenario, Monju, Japan's controversial experimental fast-breeder reactor transfers to a new organization and the Fugen advanced thermal reactor would go to JAERI. To stop over-expansion of JAERI, which already has 2,400 employees, RIKEN would take full responsibility for SPring-8. PNC's uranium enrichment facilities in Ningyo-Toge, Okayama Prefecture, would be transferred to private electrical power companies in Japan or offered for sale to overseas companies in Britain and France.

Despite widespread reports of the proposals, STA officials say that none is under active consideration at this stage, and many other proposals have been put forward.
Nevertheless, one STA official says that the likelihood of the accelerator being handed over to RIKEN is "low". He argues that such a move would harm the atmosphere at RIKEN which conducts multidisciplinary research - by concentrating too much research in one area. "You have to ask if it would be good for RIKEN and the future of nuclear power research in Japan," he says.

RIIKEN has not commented officially on suggestions that it might take over Spring-8. But some senior institute officials believe RIKEN has the flexibility to take on the challenge. Richard Nathan 